\title{
livros
}

Fragmentos...

\section{O professor de Medicina - Conhecimento, Experiência e Formação}

\author{
BATISTA, N.A.; SILVA, S.H.S. São Paulo: Loyola, 1998. 181 p.
}

O percurso de implantação e constituição da Medicina abriu caminhos para o ensino médico: para além de experiências clínicas, propostas pedagógicas foram sendo delineadas com destaque para a observação cuidadosa, a descrição detalhada, o estudo sistemático dos casos e o hospital como lugar privilegiado da prática médica e, portanto, do ensinar e do aprender em Medicina. (p.19)

A organização
do processo de
formação do
médico foi
sendo
produzida em
meio à
constituição da
medicina como
prática e como
ciência,
refletindo as
opções feitas
em relação ao
profissional que
se desejava
formar. (p.20)

Por um lado, a função docente em Medicina caracteriza-se pela complexidade, diversidade, multideterminação, dinamicidade, exigindo a interdisciplinaridade. Por outro, a formação em medicina implica triangulação entre conhecimentos, habilidades e atitudes, concretizada nos espaços de ensino, pesquisa $e$ extensão que envolvem os condicionantes relativos à missão e ao processo de desenvolvimento curricular, ao planejamento de ensino, à interação professor-aluno, à produção de conhecimento sobre a própria função docente e à atividade assistencial. (p.48) homem". (p.37)
Capra (1982) aponta para a predominância do modelo biomédico na formação e no exercício profissional do médico, sendo ressaltada uma concepção mecanicista da vida. (...) o autor aponta a tendência à concentração em partes cada vez menores do corpo, fazendo com que, freqüentemente, se perca de vista o paciente como ser humano, substituindo-se o "homem doente" pela "doença do

DOCÊNCIA EM MEDICINA

... quem é o professor que tem assumido a mediação neste processo de formação? Como tem ocorrido o seu preparo para a função docente? A pesquisa da CINAEM (Comissão Interinstitucional Nacional de Avaliação do Ensino Médico) nos traz dados importantes sobre o docente de Medicina. (...) "para a grande maioria dos entrevistados, a docência constituiu-se como atividade complementar à profissão médica. (...) Como decorrência deste perfil docente, a educação médica parece caracterizar-se como um processo de reprodução endógena, sem ênfase na produção do conhecimento".(p.50)

A racionalidade didático-pedagógica, entendida como reflexão crítica, consistente e conseqüente sobre o processo educativo que está sob a responsabilidade do professor permanece, de modo geral, como algo separado do investimento na competência técnica em Medicina. (p.52) 
Teorizar e praticar a ação educativa em uma perspectiva integradora, superando a fragmentação $e$ despolitização, características do ensino superior ao longo de sua história, é um dos desafios que se colocam para aqueles que têm como horizonte um projeto de universidade comprometido com o processo de transformação democrática. (p.47)
As disciplinas Pedagogia Médica e Didática Especial representam um momento intencionalmente colocado na pós-graduação stricto sensu em Medicina com o objetivo de formar o professor: vindo de uma trajetória acadêmica que não tematiza nem mesmo a dimensão educativa do exercício profissional do médico, e que enfatizou a chamada competência técnica, o pós-graduando tem, em muitos casos, a primeira oportunidade de discutir aspectos da docência universitária e do ensino médico. (p.61)
A organização das disciplinas Pedagogia Médica e Didática Especial nos programas oficiais de pós-graduação em Medicina no Brasil tem sido, freqüentemente, considerada um desafio. A interdisciplinaridade, as peculiaridades $e$ expectativas da clientela, a carência de professores habilitados a desenvolvê-las e a escassez de pesquisas sobre a formação do professor de Medicina são características que apontam para a necessidade de estudos nessa área. (p.63)
Masetto (1988), analisando essas disciplinas na Pós-Graduação, identifica quatro tendências em suas organizações. A primeira tendência ele considera legalista, consistindo em cursos ministrados para cumprir um dispositivo legal. (...) A segunda tendência identificada é a tecnicista, baseada em técnicas que facilitem $e$ aperfeiçoem a comunicação. A terceira é a filosófica, privilegiando os aspectos sócio-ideológicos da educação. Finalmente, a quarta é a tendência multidimensional, segundo a qual os cursos estabelecem como ponto de partida $e$ referencial para trabalhar na sala de aula os problemas nela vividos, as possíveis soluções para os mesmos, a discussão e o treinamento de técnicas pedagógicas.

Com muita freqüência observa-se a tendência legalista nas disciplinas de formação didáticopedagógica dos cursos de Pós-Graduação.

A tendência tecnicista também é bastante recorrente, reduzindo a disciplina ao domínio de recursos instrumentais que, supostamente, asseguram a eficiência ao trabalho do professor na condução do ensino. (p.59)

Tomá-las como práticas de formação, procurando compreendê-las pelo olhar de docentes que a desenvolvem, pela análise de planos de ensino e pela observação de uma experiência concreta no âmbito das referidas disciplinas, permitiu uma fecunda aproximação com sentidos e significados que assumem em diferentes contextos acadêmicos. (p.63) 
Entendemos ... que a pedagogia ao apreender a dinâmica dos processos educativos em sua concretude e ao manter trocas com outros campos do saber científico, elabora (ou deveria elaborar) uma teoria da prática pedagógica, a qual ilumina os fazeres no que tange à explicitação das lógicas que os orientam.

Articulada a essa concepção de pedagogia, emerge a de didática: de modos diversos aparece expressa como campo do domínio instrumental (técnicas, planejamento $e$ avaliação) que o professor precisa ter para realizar seu trabalho educativo. Esse domínio ora surge como quase auto-suficiente ora assume caráter instrumental que somente adquire significado em meio a problematização sobre os valores, idéias e crenças que dirigem um dado trabalho pedagógico. (p.72-3)
Concepções do processo de formação nas disciplinas pedagógicas:

as ambigüidades e contradições que têm caracterizado o uso de expressões como atitude reflexiva, curso voltado para a reflexão, ensino reflexivo, podem ser apreendidas, ainda, quando analisamos os objetivos, os conteúdos e as metodologias: assumindo a reflexão como eixo privilegiado nas disciplinas, que objetivos definimos como importantes? Que conteúdos parecem fomentar de maneira especial a reflexão? As estratégias de ensino escolhidas coadunam-se com uma proposta que se quer reflexiva? (p.66)

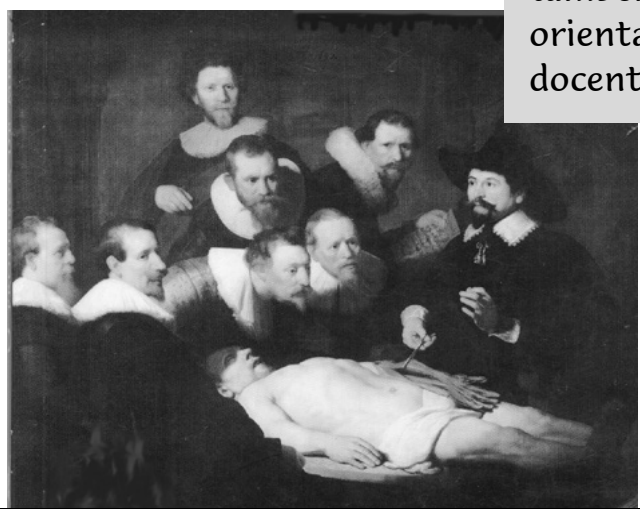

A riqueza dessa observação reside, por um lado, na explicitação de que a opção pela estratégia anuncia, também, os valores que orientam o fazer ocente. (p.68)

o reconhecimento da incompletude dos saberes, de que estes não podem resumir-se às experiências, implicando na construção de instrumentos teóricos e metodológicos que permitam analisar a docência para além das vivências e/ou dos modelos pré-estabelecidos, e a percepção de que articular com profissionais de áreas diferentes amplia possibilidades e descortina ângulos não visualizados, delineiam uma atitude interdisciplinar e um saber docente como uma construção plural e multideterminada.

nem o professor que é pedagogo ou psicólogo da educação nem o que é médico dão conta, isoladamente, da tarefa de formar o docente de Medicina. O movimento dos professores são exemplos significativos da busca de parceiros na difícil construção de práticas interdisciplinares. (p.77-8) 
No bojo desse cenário institucional complexo e das trajetórias de formação do profissional que trabalha com o ensino e sobre ele produz conhecimento, identificaram-se perspectivas docentes:

A perspectiva docente que centra o processo de formação no professor coaduna-se com a tradição existente no ensino. A transmissão parece ser o eixo das interações em sala de aula. (p.79)

Na segunda perspectiva ... A atitude interdisciplinar se anuncia, identificando que o espaço universitário pode e deve criar núcleos de interlocução entre diferentes áreas do conhecimento. (p.81)

Uma terceira perspectiva é aquela do diálogo entre professor e aluno, procurando não somente ampliar o conhecimento relativo à docência, mas articulá-lo no concreto das ações de professores de Medicina (p.83).
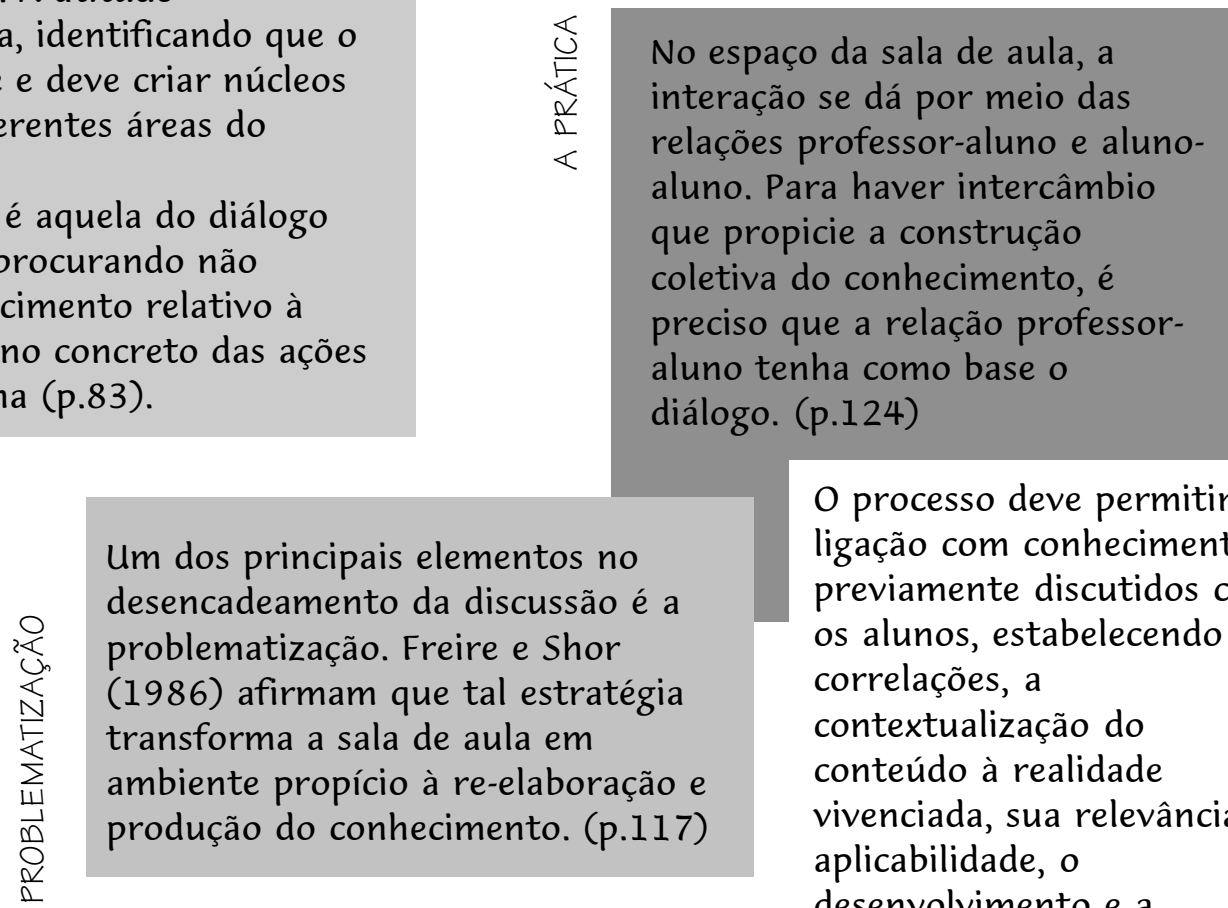

O processo deve permitir a ligação com conhecimentos previamente discutidos com os alunos, estabelecendo as correlações, a contextualização do conteúdo à realidade vivenciada, sua relevância $e$ aplicabilidade, $o$ desenvolvimento $e$ a conclusão ou síntese dos

Há necessidade de uma atitude crítica aspectos discutidos. (p.115) do professor perante a escolha do procedimento, apresentando situações desafiadoras para seus alunos $e$, assim, ajudando-os na incorporação de novos conhecimentos. (...) A técnica, por si só, não garante a qualidade da educação médica, porém, em uma discussão mais ampla do fazer docente, a sua escolha, desde que contextualizada num processo reflexivo sobre a graduação e relacionada a um planejamento efetivo, desempenha importante papel no processo ensinoaprendizagem do curso médico. (p.124) 
A avaliação deve subsidiar todo processo, fundamentando novas decisões, direcionando os destinos do planejamento e reorientando-o caso esteja se desviando dos objetivos delineados. (p.128)

A seleção de técnicas ou instrumentos de avaliação deve considerar os objetivos do ensino e da aprendizagem, a natureza da área de estudo, os métodos e procedimentos usados e o número de alunos. (p.149)

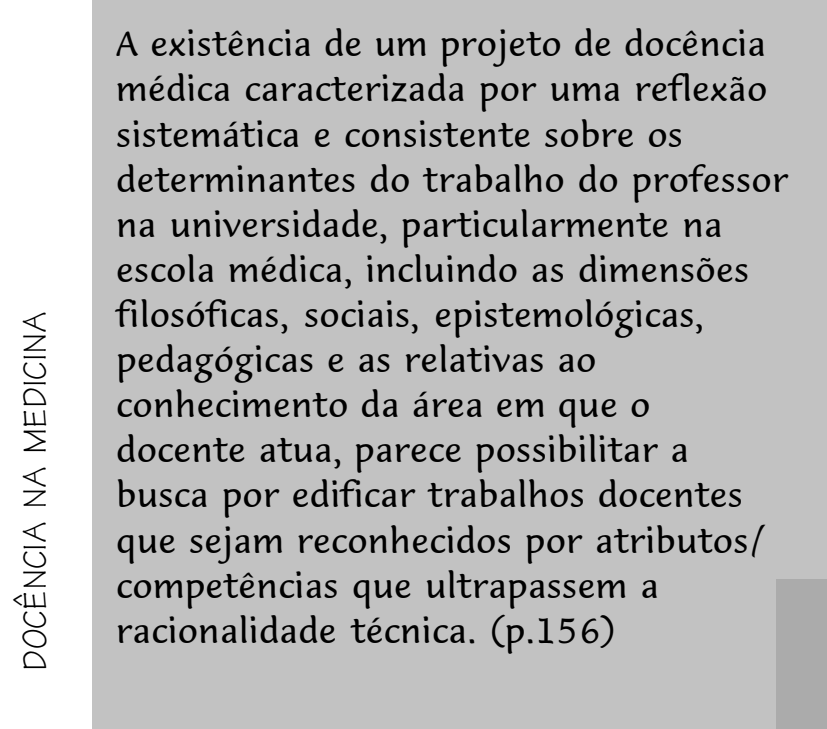

Essa formação terá que instrumentalizar o docente para uma análise que assuma a incompletude e a transitoriedade do conhecimento, delineando uma mediação que se caracterize por competências do professor no campo do domínio do conteúdo, da produção do conhecimento, da organização do processo de comunicação do ensino e das experiências de aprendizagem, das implicações éticas, humanas $e$ sociais, enfim, que esteja orientada para um ensino prospectivo. (p.165)

O bom professor, longe

CONSTRUÇÃO de ser uma abstração, é

CONTÍNUA uma construção

contínua de todo o

docente comprometido

com uma formação

profissional que

extrapole a mera

aprendizagem de

procedimentos $e$

técnicas. (p.169)
AVALIAÇÃO
As concepções presentes quanto à formação de professores, por serem múltiplas, geram perspectivas do que deve ser privilegiado quando se pensa sobre o que constitui o processo de formar um docente. As diferenças e as convergências entre estas perspectivas se explicitam, por exemplo, quando comparamos o que os pesquisadores colocam como importante para definir o que deve saber um professor ou o que deve caracterizar a prática docente. (p.165) orgs.

Maria Lúcia Toralles Pereira Miriam Celí Pimentel Porto Foresti Departamento de Educação 